\title{
ANALISIS RENTANG HARGA GULA KRISTAL RAFINASI PADA PASAR LELANG KOMODITAS DENGAN PENDEKATAN HARGA PARITAS
}

\section{PRICE RANGE ANALYSIS FOR REFINED SUGAR IN COMMODITY AUCTION MARKET WITH PARITY PRICE APPROACH}

\author{
Bagus Wicaksena
}

\author{
Pusat Kebijakan Perdagangan Dalam Negeri, Badan Pengkajian dan \\ Pengembangan Kebijakan Perdagangan - Kementerian Perdagangan \\ JI MI Ridwan Rais No 5, Jakarta Pusat 10110 \\ bagus.wicaksena@gmail.com
}

Naskah diterima: 18 September 2017, revisi: 16 November, disetujui: 20 Desember 2017

\begin{abstract}
The government has stipulated Trade Minister Regulation Number 16/M-DAG/ PER/3/2017 regarding Refined Sugar Trade in Commodity Auction Market. However, the method of determining the highest and the lowest sugar price has not been arranged in the regulation. Thus, this study aims to analyze the price range of Refined Sugar in Commodity Auction Market. Import parity approach of raw sugar is utilized to calculate auction price range. The cost components are highest and lowest raw sugar price in international market as well as tolling fee for production and distribution of refined sugar. The result indicates that the estimated lowest price is between IDR 7,869/Kg and IDR 8,176/Kg and the estimated highest price is between IDR $11,527 / \mathrm{Kg}$ and IDR $11,742 / \mathrm{Kg}$. This study recommends that import parity approach of raw sugar can be used to determine the price range of refined sugar. However, technical guidance for seller/buyer with existing sales contracts, technical team consisting representative of stakeholders to anticipate the fluctuating price issue, and the certainty of import quota for raw sugar as supply guarantee of refined sugar in action market are needed to be considered in order to support the regulation.
\end{abstract}

Keywords: Refined Sugar, Auction Market, Parity Price

\begin{abstract}
Abstrak
Pemerintah menerbitkan Peraturan Menteri Perdagangan Nomor 16/M-DAG/PER/3/ 2017 Tentang Perdagangan Gula Kristal Rafinasi(GKR) Melalui Pasar Lelang Komoditas (PLK). Dalam regulasi dimaksud, terdapat 1 (satu) aspek dalam mekanisme lelang yang belum dicapai kesepakatan, yaitu metode penentuan Harga Batas Bawah (HBB) dan
\end{abstract}


Harga Batas Atas (HBA) penjualan GKR. Untuk menganalisis besaran rentang harga lelang GKR, digunakan pendekatan paritas impor GKM dengan komponen harga GKM tertinggi dan terendah, serta biaya tolling terkait produksi dan distribusi GKR. Besaran HBB diperkirakan berada pada kisaran Rp 7.869/Kg dan Rp 8.176/Kg dan HBA sebesar Rp 11.527/Kg dan Rp 11.742/Kg. Sebagai perangkat kebijakan, pendekatan paritas impor GKM dapat digunakan untuk menentukan rentang harga GKR. Namun demikian diperlukan beberapa pertimbangan antara lain petunjuk teknis bagi peserta lelang yang sudah memiliki kontrak penjualan, dukungan tim teknis yang terdiri dari perwakilan pemangku kepentingan untuk mengantisipasi dinamika harga GKM, serta kepastian kuota impor GKM dalam menjamin supply GKR di PLK.

Kata Kunci: Gula Rafinasi, Pasar Lelang, Harga Paritas

\section{A. PENDAHULUAN}

Saat ini, pasar gula di Indonesia tersegmentasi menjadi 2(dua) bagian yaitu pasar gula konsumsi yang dipasok oleh Pabrik Gula (PG) berbasis tebu dan pasar gula industri yang dipasok oleh PG Rafinasi berbasis Gula Kristal Mentah (GKM) impor. Berdasarkan Keputusan Presiden Nomor 57 Tahun 2004 tentang Penetapan Gula Sebagai Barang Dalam Pengawasan, PG berbasis tebu memproduksi Gula Kristal Puth (GKP) yang diperuntukkan bagi konsumen rumah tangga sedangkan PG Rafinasi memproduksi Gula Kristal Rafinasi (GKR) untuk keperluan industri. Dengan demikian, GKR tidak dapat dijual kepada konsumen dan sebaliknya, GKP tidak dapat dipasarkan kepada industri (Susila, 2005).

Namun dalam perkembangannya, dualisme pasar gula tidak berjalan dengan baik karena terdapat indikasi rembesan, terutama rembesan GKR ke pasar gula konsumsi (Tayibnapis et. al, 2016). Beberapa faktor yang dianggap mendorong terjadinya rembesan antara lain kualitas dan harga GKR yang relative lebih baik dibandingkan dengan GKP (Hartanto, 2014 dan Fajrin, Hartono, \& Waluyati, 2015). Hal ini tentunya berdampak pada kesejahteraan petani tebu sebagai pelaku utama pemasok produsen GKP (Marpaung et. al, 2011). Selama tahun 2013 - 2016, terdapat sekitar 400 ton GKR dijual di tingkat pengecer serta sekitar 450 ribu ton yang berpotensi rembes (Kemendag, 2016). Lebih lanjut, dualisme pasar gula juga dianggap tidak memberikan dampak positif dalam mendorong pertumbuhan industri skala kecil. Haryana dan Wicaksena (2016) menjelaskan bahwa setelah diterbitkannya Surat Menteri Perdagangan Nomor 1300/M-DAG/SD/ 12/2014 yang mewajibkan distribusi GKR secara langsung dari importir kepada industri makanan dan minuman pada tatanan implementasinya perlu didukung dengan bukti kontrak bisnis.

Sekitar 85\% produksi GKR dikonsumsi oleh industri makanan dan minuman yang berskala relatif besar dan hanya sekitar 15\% yang dapat diserap oleh industri makanan dan minuman skala kecil atau rumah tangga (IKM). Pengaturan distribusi GKR, terutama bagi IKM, berpotensi menghambat akses IKM atas GKR mengingat pengaturan distribusi belum jelas serta kemampuan IKM yang dapat melakukan kontrak bisnis dengan produsen GKR masih rendah. Lebih lanjut, peraturan lain terkait distribusi GKR pada Pasal 13 dalam Peraturan Menteri Perdagangan Nomor 74/M-DAG/PER/9/2015 Tentang Perdagangan Antarpulau Gula Krista Rafinasi secara eksplisit diatur bahwa distribusi GKR melalui distributor dapat dilakukan hanya dalam kondisi tertentu dan memerlukan rekomendasi dari Menteri Perindustrian dan/atau UMKM. Dengan demikian, tidak sedikit IKM makanan dan minuman yang terpaksa membeli GKP sebagai bahan baku. Padahal, kualitas dan harga GKP relatif tidak lebih baik dan kompetitif dibandingkan dengan GKR. 
Atas pertimbangan potensi rembesan GKR sekaligus memberikan akses yang sama bagi industri makanan dan minuman skala besar, menengah, dan kecil, Pemerintah telah menerbitkan Peraturan Menteri Perdagangan Nomor 16/M-DAG/PER/3/2017 Tentang Perdagangan Gula Kristal Rafinasi Melalui Pasar Lelang Komoditas. Sebagai tindaklanjut, telah ditetapkan PT Pasar Komoditas Jakarta (PKJ) sebagai penyelenggara pasar lelang gula kristal rafinasi melalui Surat Keputusan Menteri Perdagangan Nomor 684/M-DAG/KEP/5/2017 tentang Penetapan Penyelenggara Pasar Lelang Gula Kristal Rafinasi. Sebagai penyelenggara lelang, PT PKJ telah menyiapkan konsep dan mekanisme lelang GKR secara online untuk dilakukan simulasi.

Namun demikian, masih terdapat 1 (satu) aspek dalam mekanisme lelang yang belum dicapai kesepakatan, yaitu metode penentuan Harga Batas Bawah (HBB) dan Harga Batas Atas (HBA) penjualan GKR yang ditetapkan oleh Menteri sebagaimana diatur dalam Pasal 11 pada Permendag dimaksud. Penentuan HBB dan HBA bersifat strategis karena menentukan dinamika lelang serta harus mempertimbangkan efisiensi dan keuntungan bagi peserta lelang. Dengan demikian, penelitian terkait penentuan rentang harga lelang perlu dilakukan. Berdasarkan hal tersebut, penelitian ini bertujuan untuk: (a) menganalisis rentang harga GKR pada Pasar Lelang Komoditas (PLK) dan (b) merumuskan rekomendasi kebijakan harga GKR pada (PLK).

\section{B. METODE PENELITIAN}

Untuk menganalisis besaran rentang harga lelang GKR, digunakan pendekatan paritas impor GKM sebagai bahan baku utama pembuatan GKR. Secara konsep, harga paritas merupakan metode perhitungan harga yang mengacu pada hukum satu harga (the law of one price) yang menjelaskan bahwa pada dasarnya harga suatu produk relatif sama di setiap tempat/pasar namun dapat menjadi berbeda-beda dikarenakan adanya perbedaan marjin distribusi di setiap tempat (USAID, 2008). Harga paritas memiliki beberapa keunggulan diantaranya digunakan sebagai pendekatan yang mendukung kebijakan dukungan harga bagi produsen, termasuk menjamin keuntungan yang layak bagi produsen (Erba dan Novakovic, 1995), pengukur insentif bagi produsen untuk melakukan produksi dan distribusi, serta penciptaan harga yang efisien melalui deteksi adanya perdagangan yang tidak adil (USAID, 2008). Pendekatan paritas impor juga umum digunakan untuk komoditas yang dominan berasal dari impor (Salam, 2009). Hal ini sejalan dengan fakta bahwa GKM yang diolah menjadi GKR seluruhnya berasal dari impor. Pendekatan paritas impor berbasis pada harga free on board (fob) ditambah dengan beberapa komponen biaya. Muslim (2014) menggunakan komponen harga fob, premium, freight, asuransi, bea masuk, pajak, handling, dan marjin distribusi dalam menghitung paritas impor kedelai. Dalam studi tersebut, penghitungan harga paritas dilakukan pada tingkat importir hingga eceran.

Lebih jauh, dengan mengacu pada Gode dan Sunder (2003), harga paritas impor yang dijadikan acuan sebagai rentang harga terdiri dari harga tertinggi dan terendah berdasarkan fob selama periode tertentu, ditambah dengan beberapa komponen biaya yang terdiri dari freight, insurance, premium, pajak, bongkar muat, cost of fund, serta marjin produksi raw sugar menjadi GKR. Dalam penelitian ini, harga paritas terendah merupakan acuan Harga Batas Bawah (HBB) sedangkan harga paritas tertinggi merupakan acuan Harga Batas Atas (HBA) pada pasar lelang GKR. Sebagai pembanding dan acuan harga keseimbangan GKR, maka akan digunakan dokumen pendukung terkait transaksi penjualan GKR dari produsen kepada industri pengguna.

Penelitian ini menggunakan data primer yang diperoleh melalui Focus Group Discussion (FGD) yang melibatkan Asosiasi Gula Rafinasi Indonesia (AGRI), importir GKM yang terdiri dari 11 (sebelas) perusahaan rafinasi, Gabungan Pengusaha Makanan dan Minuman (GAPMMI), dan Asosiasi Industri 
Minuman Ringan (ASRIM) yang terdiri dari prosedur dan mekanisme lelang GKR, komponen biaya paritas, dan informasi harga GKR yang dijual kepada industri makanan dan minuman. Data primer digunakan untuk menyusun komponen pada harga paritas impor, sementara data sekunder terdiri dari harga gula di pasar intenasional.

\section{KERANGKA TEORI}

Dalam tatanan teori, rentang harga dalam lelang komoditas dapat mengacu kepada konsep harga dasar (price floor) dan harga atap (price ceiling). Menurut Besanko dan Braeutigam (2011) dalam Pusat Kebijakan Perdagangan Dalam Negeri (2015), harga dasar merupakan harga minimum yang ditetapkan oleh otoritas (pemerintah) sebagai upaya memperbaiki harga barang atau jasa yang diyakini dijual pada tingkat harga yang lebih rendah dari yang layak diterima oleh produsen. Harga dasar akan efektif jika ditetapkan di atas harga ekuilibrium (harga pasar) karena bersifat mengikat (binding) dan dapat mendorong pembentukan harga yang lebih layak bagi produsen. Jika harga dasar ditetapkan di bawah tingkat harga keseimbangan maka secara konsep tidak akan memberikan dampak kepada pasar, walaupun bisa dilakukan. Sebaliknya, harga atap merupakan harga maksimum yang ditetapkan oleh otoritas (pemerintah) sebagai upaya memperbaiki harga barang atau jasa yang diyakini dijual pada tingkat harga yang lebih tinggi dari yang layak diterima oleh konsumen. Harga atap akan efektif jika ditetapkan di bawah ekuilibrium (harga pasar) dan dapat mendorong pembentukan harga yang lebih layak bagi konsumen. Jika harga atap ditetapkan di atas tingkat harga keseimbangan maka secara konsep tidak akan memberikan dampak kepada pasar. Secara umum, jika harga dasar dan harga atap bersifat binding makan akan berdampak pada kelebihan penawaran (surplus) dan kelebihan permintaan (shortage).

Konsep harga dasar (price floor) dan atap (price ceiling) umum diterapkan di negara berkembang dengan tujuan melindungi produsen dan konsumen (Akanni, 2013 dan Kornher \& Kalkuhl, 2013). Kebijakan harga tersebut tentunya akan berdampak pada penerimaan petani sebagai produsen dan konsumen sebagai pengguna produk pertanian yang diukur sebagai surplus produsen maupun konsumen. Untuk mencapai tujuan perlindungan bagi produsen maupun konsumen, maka kebijakan harga harus bersifat mengikat (binding) walaupun akan berdampak terjadinya surplus maupun shortage, sebagaimana dijelaskan secara konsep dalam Gambar 1 berikut.

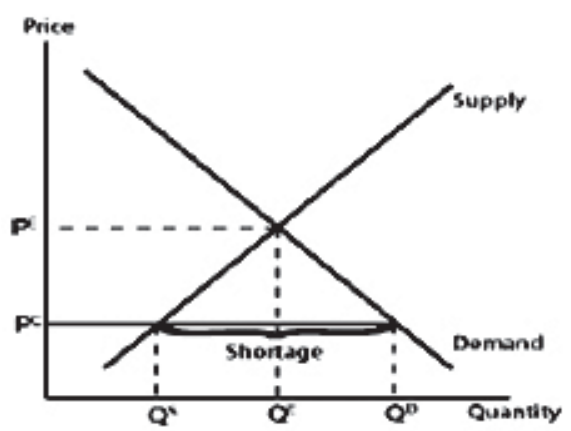

(a)

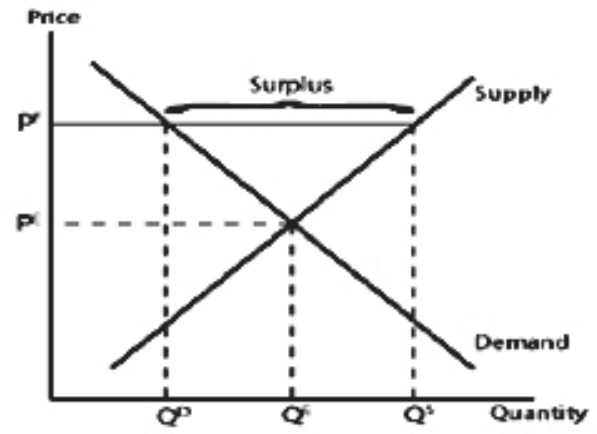

(b)

Sumber: Puska Dagri (2015)

Gambar 1.

Partial Equilibrium Pada Price Ceiling (a) dan Price Floor (b) 
Namun demikian, tidak sedikit permasalahan yang dijumpai di negara berkembang dimana kebijakan rentang harga tidak bersifat binding (non-binding), yaitu harga dasar ditetapkan lebih rendah dari harga pasar (ekuilibrium) dan harga atap ditetapkan lebih tinggi dari harga pasar (ekuilibrum) sebagaimana dijelaskan dalam Gambar 2. Secara konsep, hal tersebut akan berdampak pada tidak efektifnya penetapan rentang harga komoditas pertanian karena bersifat tidak memaksa. Kasus tersebut dapat terjadi diantaranya karena kesalahan perkiraan dalam menentukan harga pasar yang wajar atau tujuan pemerintah yang tidak ingin mendistorsi pasar (Galtier, 2013).

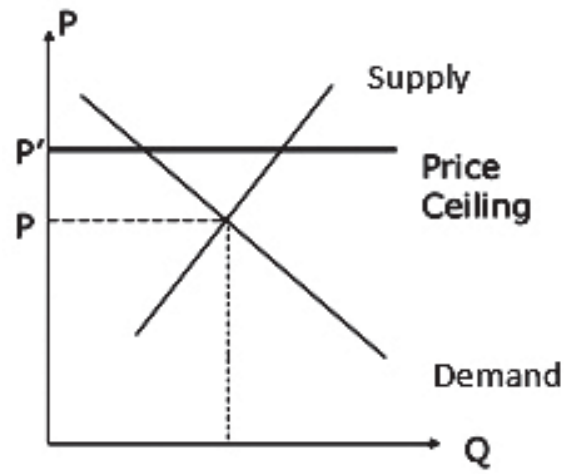

(a)

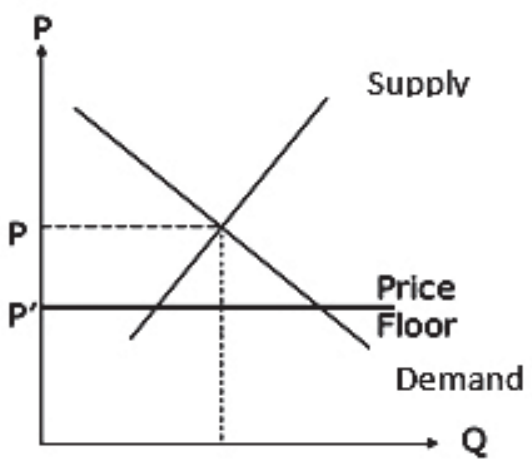

(b)

Sumber: Puska Dagri (2015)

Gambar 2.

Partial Equilibrium Pada Non-Binding Price Ceiling (a) dan Non-Binding Price Floor (b)

Dalam konteks lelang komoditas, price floor dan price ceiling dapat diterapkan dan bersifat non-binding. Konsep tersebut menjadi studi oleh Smith dan Williams (1981) yang pada dasarnya menjelaskan bahwa pengendalian harga yang tidak mengikat, baik melalui harga atap dan harga dasar, memiliki dampak yang relatif baik dalam mempertahankan pasar yang bersaing (competitive market). Dalam studi tersebut, rentang harga dibentuk dalam percobaan dengan sistem Programmed Logic for Automated Teaching Operation (PLATO) yang dilakukan pada New York Stock Exchange dan diumumkan secara terbuka kepada peserta lelang. Hasil studi menunjukkan bahwa harga yang terbentuk berada pada harga atap (price ceiling) pada saat penjual memiliki posisi tawar yang relatif lebih baik dibanding pembeli. Sebaliknya, harga akan berada pada kisaran harga dasar (price floor) jika posisi pembeli relatif lebih kuat dibandingkan penjual. Gode dan Sunder (2003) juga melakukan studi eksperimental harga atap dan harga dasar yang bersifat non-binding dengan model lelang berganda. Dalam hal ini, harga dasar (price floor) ditetapkan di bawah ekuilibrium dan harga atap (price ceiling) ditetapkan di atas ekuilibrium berdasarkan rentang tertinggi dan terendah dalam penawaran. Walaupun terdapat potensi bahwa seller dapat menggunakan harga atap yang tidak mengikat sebagai acuan atau "focal point" untuk berkolusi menentukan acuan harga jual, namun secara keseluruhan keberadaan rentang harga yang tidak mengikat akan meningkatkan efisiensi perdagangan. Hal ini dikarenakan tidak adanya retrading, sehingga penjual dapat menjual langsung produknya kepada pembeli dan bagi penjual yang melakukan penawaran di atas harga atap akan tersisih (excluded). Gambar 3 berikut menjelaskan kerangka berpikir penelitian ini. 


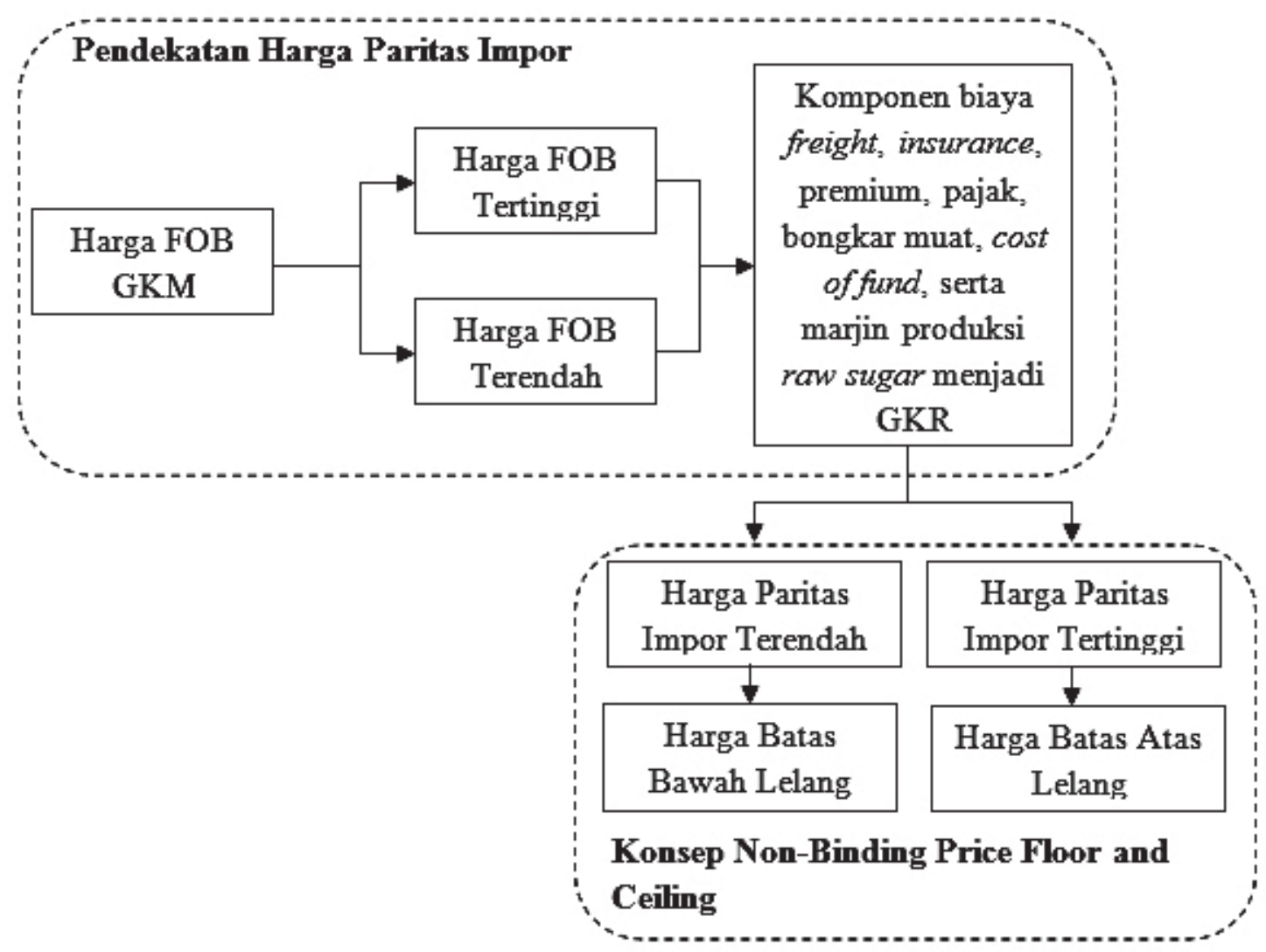

Gambar 3.

Kerangka Berpikir Penelitian

\section{HASIL DAN PEMBAHASAN}

\section{Konsep Lelang GKR melalui PLK}

PT Pasar Komoditas Jakarta (PKJ) sebagai penyelenggara pasar lelang gula kristal rafinasi melalui Surat Keputusan Menteri Perdagangan Nomor 684/M-DAG/KEP/5/2017 tentang Penetapan Penyelenggara Pasar Lelang Gula Kristal Rafinasi. Sebagai penyelenggara lelang, PT PKJ telah memiliki izin dari Kementerian Perdagangan sebagai penyelenggara pasar lelang spot dan forward dengan nomor 44/BAPPEBTI/Kep-PL/SP/12/2016. Dalam pelaksanaannya, terdapat beberapa perusahaan yang berkolaborasi dengan PT PKJ sebagai penyelenggara lelang, diantaranya adalah PT Sucofindo, PT Kliring Berjangka Indonesia, PT Bursa Berjangka Jakarta, dan PT Limakilo Majubersama Petani. Fungsi dari perusahaan tersebut antara lain sebagai berikut:

a. PT Sucofindo sebagai lembaga yang melakukan kegiatan di Gudang dalam rangka verifikasi kepemilikan Komoditas Peserta Jual.

b. PT Kliring Berjangka Indonesia (KBI) sebagai lembaga yang memberikan penjaminan penyelesaian transaksi dari Peserta Beli dan Peserta Jual.

c. PT Bursa Berjangka Jakarta (BBJ) sebagai Bursa Berjangka yang menyediakan sistem perdagangan komoditas.

d. PT Limakilo Majubersama Petani sebagai software house yang menggintegrasikan semua lembaga terkait secara online. 
Dalam implementasinya, terdapat beberapa ketentuan yang diharapkan dapat menjamin kelancaran pelaksanaan lelang dan sudah mengakomodir kepentingan seluruh peserta lelang, yang terdiri dari penyerahan, biaya, jaminan, retur barang, harga batas, prioritas untuk UMKM, penetapan biaya lelang, dan traceability. Adapun penjelasannya sebagai berikut:

a. Penyerahan GKR dapat dilakukan baik di gudang produsen (loco) maupun gudang pembeli (franco).

b. Biaya lelang terdiri dari biaya kepesertaan bagi penjual sebesar Rp 10 juta sebagai pendaftaran dan Rp 25 juta sebagai iuran tahunan. Sementara untuk pembeli, biaya pendaftaran sebesar Rp 1 juta dan tidak ada iuran tahunan. Terkait biaya transaksi, penjual harus membayar fee sebesar Rp 100 ribu per ton untuk setiap transaksi sementara pembeli tidak dibebankan fee transaksi. Sedangkan untuk tahap awal, biaya yang dikenakan diusulkan sebesar Rp 85 ribu per ton.

c. Jaminan yang harus diserahkan terdiri dari 2 (dua) hal yaitu jaminan transaksi sebesar $5 \%$ dari nilai yang akan ditransaksikan yang dapat berbentuk uang, deposito, atau surat hutang (bond).

d. Retur dapat dilakukan oleh pembeli paling lambat 2 (dua) minggu setelah barang diterima di gudang pembeli.

e. Terdapat penetapan batas harga yang saat ini diusulkan hanya berupa ceiling price.

f. Prioritas bagi UMKM/IKM untuk diupayakan minimal 20\% kuota GKR dalam PLK.

g. Biaya lelang ditetapkan oleh Pemerintah, dalam hal ini Kementerian Perdagangan melalui Bappebti.

Sebelum pelaksanaan lelang, setiap calon peserta jual dan peserta beli melakukan registrasi secara online kepada PT PKJ dengan melampirkan dokumen persyaratan. Peserta jual merupakan produsen GKR yang telah mendapatkan izin produksi dari instansi yang berwenang sementara peserta beli merupakan pengguna GKR yang sudah diverifikasi oleh dinas propinsi atau kabupaten/kota yang membidangi perdagangan. Adapun dokumen yang menjadi persyaratan bagi peserta jual dan peserta beli ditampilkan dalam Tabel 1 berikut. 
Tabel 1.

Dokumen Persyaratan Peserta Lelang GKR

\begin{tabular}{|c|c|}
\hline $\begin{array}{r}\text { Peserta Jual } \\
\end{array}$ & Peserta Beli \\
\hline Akta Pendirian Perusahaan & Badan Hukum \\
\hline $\begin{array}{l}\text { Anggaran Dasar dan Perubahan terakhir } \\
\text { yang mencantumkan direksi dan komisaris }\end{array}$ & Akta Pendirian Perusahaan \\
\hline $\begin{array}{l}\text { Surat pengesahan, persetujuan dan/atau } \\
\text { penerimaan dari Kemenkumham dan/atau } \\
\text { penerimaan pemberitahuan kepada } \\
\text { Kemenkumham }\end{array}$ & $\begin{array}{l}\text { Anggaran Dasar dan Perubahan terakhir } \\
\text { yang mencantumkan direksi dan komisaris }\end{array}$ \\
\hline Kartu Identitas Direksi & $\begin{array}{l}\text { Surat pengesahan, persetujuan dan/atau } \\
\text { penerimaan dari Kemenkumham dan/atau } \\
\text { penerimaan pemberitahuan kepada } \\
\text { Kemenkumham }\end{array}$ \\
\hline Nomor Pokok Wajib Pajak & Kartu Identitas Direksi \\
\hline $\begin{array}{l}\text { Surat Keterangan Domisili } \text { Perseroan } \\
\text { (SKDP) }\end{array}$ & Nomor Pokok Wajib Pajak \\
\hline Surat Izin Usaha Perdagangan (SIUP) & $\begin{array}{l}\text { Surat Keterangan } \\
\text { (SKDP) }\end{array}$ \\
\hline Tanda Daftar Perusahaan (TDP) & Surat Izin Usaha Perdagangan (SIUP) \\
\hline Surat Pernyataan Keanggotaan & Tanda Daftar Perusahaan (TDP) \\
\hline $\begin{array}{l}\text { Persetujuan Impor yang masih dimiliki dan } \\
\text { masih berlaku }\end{array}$ & Surat Pernyataan Keanggotaan \\
\hline Angka Pengenal Impor - Produsen (API-P) & Perizinan dari Kementerian terkait \\
\hline Nomor Induk Kepabeanan (NIK) & Surat Pengukuhan Kena Pajak \\
\hline \multicolumn{2}{|l|}{ Domisili Gudang } \\
\hline Surat Pernyataan Kepesertaan Jual & Badan Usaha \\
\hline Surat Izin Usaha Industri & Akta Pendirian Perusahaan \\
\hline \multirow[t]{5}{*}{ Surat Pengukuhan Kena Pajak } & $\begin{array}{l}\text { Kartu Identitas Seluruh Direksi/Penanggung } \\
\text { Jawab }\end{array}$ \\
\hline & Nomor Pokok Wajib Pajak \\
\hline & $\begin{array}{lll}\begin{array}{l}\text { Surat Keterangan } \\
\text { (SKDP) }\end{array} & \text { Domisili Perseroan } \\
\end{array}$ \\
\hline & Surat Izin Usaha Perdagangan (SIUP) \\
\hline & Surat Pernyataan Keanggotaan \\
\hline
\end{tabular}

Sumber: PT PKJ (diolah)

Setelah proses registrasi dan verifikasi dokumen selesai, Peserta Jual (PJ) dan Peserta Beli (PB) mengirimkan informasi kepada PT PKJ terkait kuantitas dan kualitas barang yang akan dilelang. Kemudian, PJ memberikan jaminan risiko transaksi berupa bukti kepemilikan barang dalam gudang yang dikuasai oleh PJ yang akan diverifikasi oleh PT Sucofindo. Pada saat yang bersamaan, PJ akan menyetorkan sejumlah dana tunai (deposit) dengan persentase tertentu dari nilai barang tersebut kepada PT KBI sebagai jaminan bahwa PJ akan menyerahkan barang kepada PB. Pada sisi lain, PB juga akan menyetorkan sejumlah dana (deposit) dengan persentase tertentu kepada PT KBI sebagai jaminan bahwa PB akan membeli barang dari PJ. Setelah deposit diterima oleh PT KBI, maka akan dilakukan verifikasi oleh PT BBJ untuk dicatat dalam sistem sehingga bisa diakses oleh kedua belah pihak. 
Tahap selanjutnya, PJ dan PB melakukan proses lelang secara online untuk mencapai kesepakatan kualitas, kuantitas, harga, dan lokasi penyerahan. Adapun harga yang disepakati berada dalam rentang harga yang telah ditetapkan Pemerintah. Mekanisme lelang bersifat many-to-many dimana masing-masing PJ dan PB dapat melakukan penawaran kepada seluruh peserta lelang secara langsung secara transparan. Setelah dicapai kesepakatan, maka PB akan memberikan konfirmasi jadwal pengambilan kepada PT Sucofindo yang pada proses sebelumnya telah melakukan verifikasi barang PJ. Pengambilan barang dapat bersifat loco (di gudang PJ) atau franco (di gudang PB). Namun demikian, sebelum dilakukan pengambilan barang, PB wajib melakukan pelunasan transaksi melalui PT KBI yang besarannya merupakan selisih dari harga yang disepakati dengan deposit yang dilakukan sebelumnya. Dalam hal ini, PT PKJ mengisyaratkan pembayaran dilakukan dalam waktu 1 (satu) bulan.

Setelah PB melakukan pelunasan yang dibayarkan kepada PT KBI, PB akan menerima electronic D-O sebagai dokumen yang disertakan saat pengambilan barang. Selanjutnya, PT KBI akan melakukan pembayaran kepada PJ dengan total sekitar 90\% dari nilai transaksi. Adapun sisanya (sekitar 10\%) akan dilakukan setelah PB melakukan pengambilan barang. Dalam rangka mendukung efisiensi pembayaran dan penyerahan barang, PT PKJ dapat memberikan referensi kepada PB dan PJ berupa fasilitas pembiayaan, jasa logistik, dan transportasi. Secara umum, mekanisme lelang dijelaskan dalam Gambar 4 berikut.

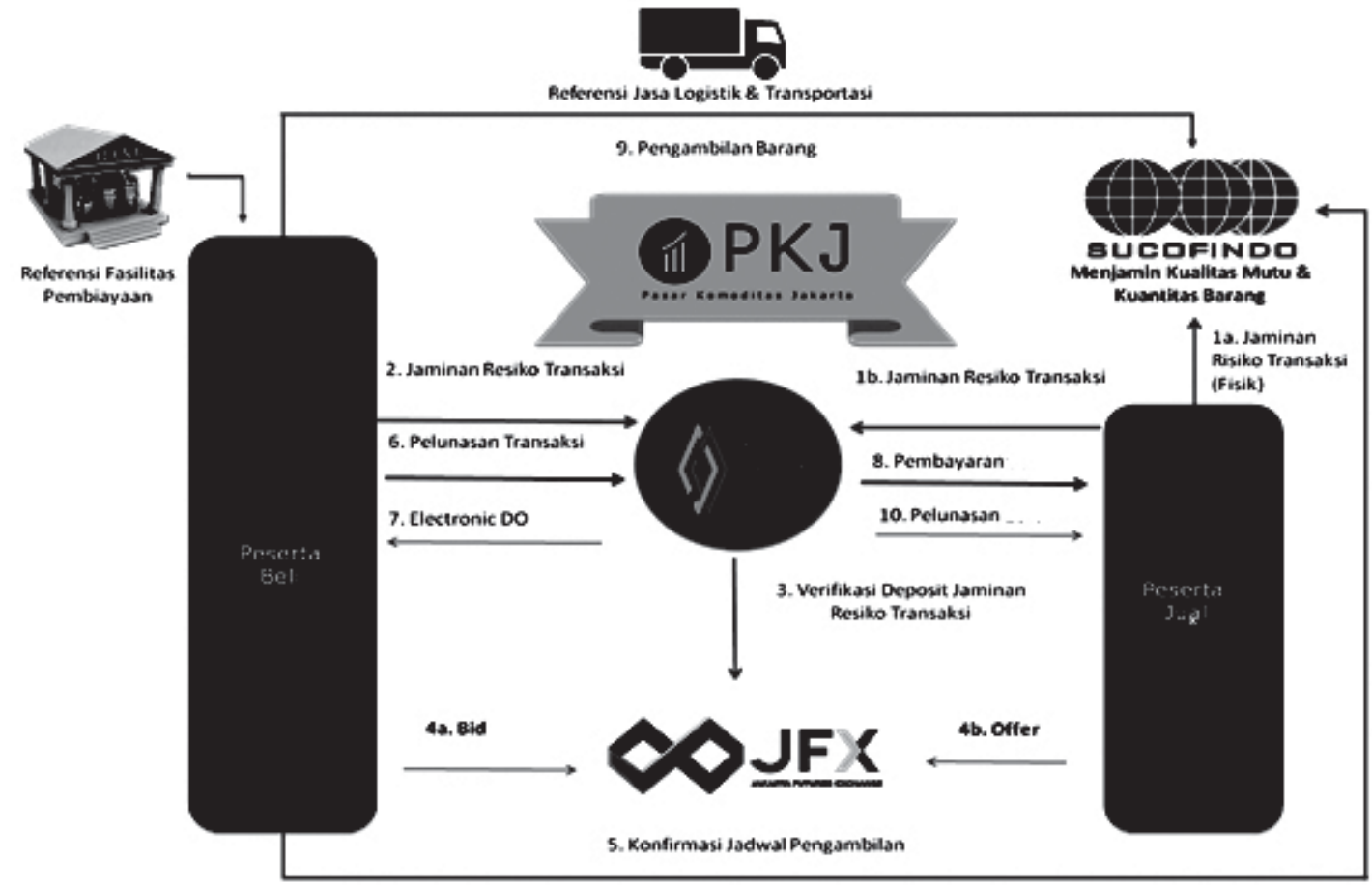

Gambar 4.

Mekanisme Lelang GKR dalam PLK

(Sumber : PT. Pasar komoditas Jakarta dan Bappebti, data primer (diolah))

\section{Komponen Biaya Paritas}

Perhitungan HBB dan HBA berdasarkan harga paritas impor eceran menggunakan komponen biaya yang diperoleh melalui Focus Group Discussion (FGD) dengan produsen GKR, industri makanan dan minuman, dan Asosiasi Logistik Forwarding Indonesia. Besaran komponen harga paritas terdiri dari: 
a. Premium, mengacu kepada informasi dari perusahaan di Australia dimana istilah premium terdiri dari dari polarisation premium sebesar AUD 14/Ton ditambah physical sales premium sebesar AUD 30/Ton, menjadi AUD 54/Ton atau setara dengan US\$39,96/Ton (dengan asumsi AUD 1 = US\$ 0,74).

b. Freight dan Insurance sebesar US\$24/Ton.

c. Bea Masuk sebesar Rp 550/Kg untuk Most Favored Nation (MFN) dengan pertimbangan fleksibilitas dalam perhitungan, mengingat Indonesia dapat mengimpor GKM dari seluruh negara eksportir yang belum memiliki kerjasama perdagangan, selain dari Thailand dan Australia.

d. Pajak Pertambahan Nilai (PPN) GKM sebesar 10\% dan Pajak Penghasilan sebesar 2,5\%, serta PPN GKR sebesar 10\% yang disesuaikan dengan besaran PPN GKM yang telah dibebankan sebelumnya.

e. Asuransi sebesar 0,37\%/Ton dari harga CIF, Provisi Letter of Credit sebesar 0,25\% dari harga CIF, biaya ekspedisi yang merupakan biaya transportasi dari pelabuhan ke gudang importir sebesar Rp 75/Kg, dan biaya bongkar muat sebesar Rp 40/Kg.

f. Biaya bank (Cost of Fund) sebesar 10\% dengan term of payment 3 (tiga) bulan, provisi kredit sebesar 1\%, biaya susut selama pengangkutan sebesar 0,5\%, serta Collateral Management Agreement (CMA) sebagai biaya agunan yang dibayarkan oleh importir selaku pemilik barang kepada surveyor selaku penyedia jasa audit dan pengurusan penjaminan. Seluruh biaya dibebankan dari total biaya handling.

g. Biaya produksi pengolahan GKM menjadi GKR dengan kisaran US\$ 66/Ton - US\$ 97/Ton (Pelitasari, 2006).

h. Biaya kehilangan selama produksi (production loss) sebesar 6\%.

Sementara untuk harga GKM, dilakukan pengamatan harga fob raw sugar yang terendah sebagai HBB dan harga fob raw sugar yang tertinggi sebagai HBA dalam periode tertentu. Untuk penelitian ini, pengamatan dilakukan pada perkembangan harga fob raw sugar pada bursa Intercontinental Exchance (ICE) dan bursa New York dengan kontrak nomor 11 (Sugar No. 11) selama periode Mei - Juli 2017 untuk perdagangan Bulan Juli 2017. Data tersebut dapat diakses melalui www.barchart.com dengan kode komoditas SBN17. Selama periode dimaksud, harga raw sugar terendah sebesar 14,6 cents/lb atau setara dengan US\$321,58/Ton, sementara harga tertinggi sebesar 23,1 cents/lb atau setara dengan US\$ 508,8/Ton. Selain menggunakan informasi hasil dari FGD, beberapa asumsi yang diperoleh dari literatur terkait juga digunakan dalam menghitung HBB dan HBA.

\section{Harga Batas Bawah}

Harga Batas Bawah (HBB) dengan pendekatan paritas impor menggunakan 2 (dua) alternatif berdasarkan besaran komponen biaya yang diperoleh dari FGD. Pada alternatif I, harga terendah raw sugar sebesar US\$321,58/Ton, besaran freight dan insurance dihitung berdasarkan Peraturan Menteri Perdagangan Nomor 07/M-DAG/PER/2/2016 Tentang Penetapan Nilai Freight dan Nilai Asuransi Dalam Pengisian Pemberitahuan Ekspor Barang Terkait Penggunaan Term of Delivery Cost, Insurance and Freight Untuk Pelaksanaan Ekspor Tahun 2016. Sementara itu biaya produksi mengacu pada studi Pelitasari (2006) yaitu sebesar US\$66/Ton. Sedangkan pada alternatif II, biaya freight and insurance sebesar US\$24/Ton (Tabel 2). 
Tabel 2.

Perhitungan Harga Batas Bawah

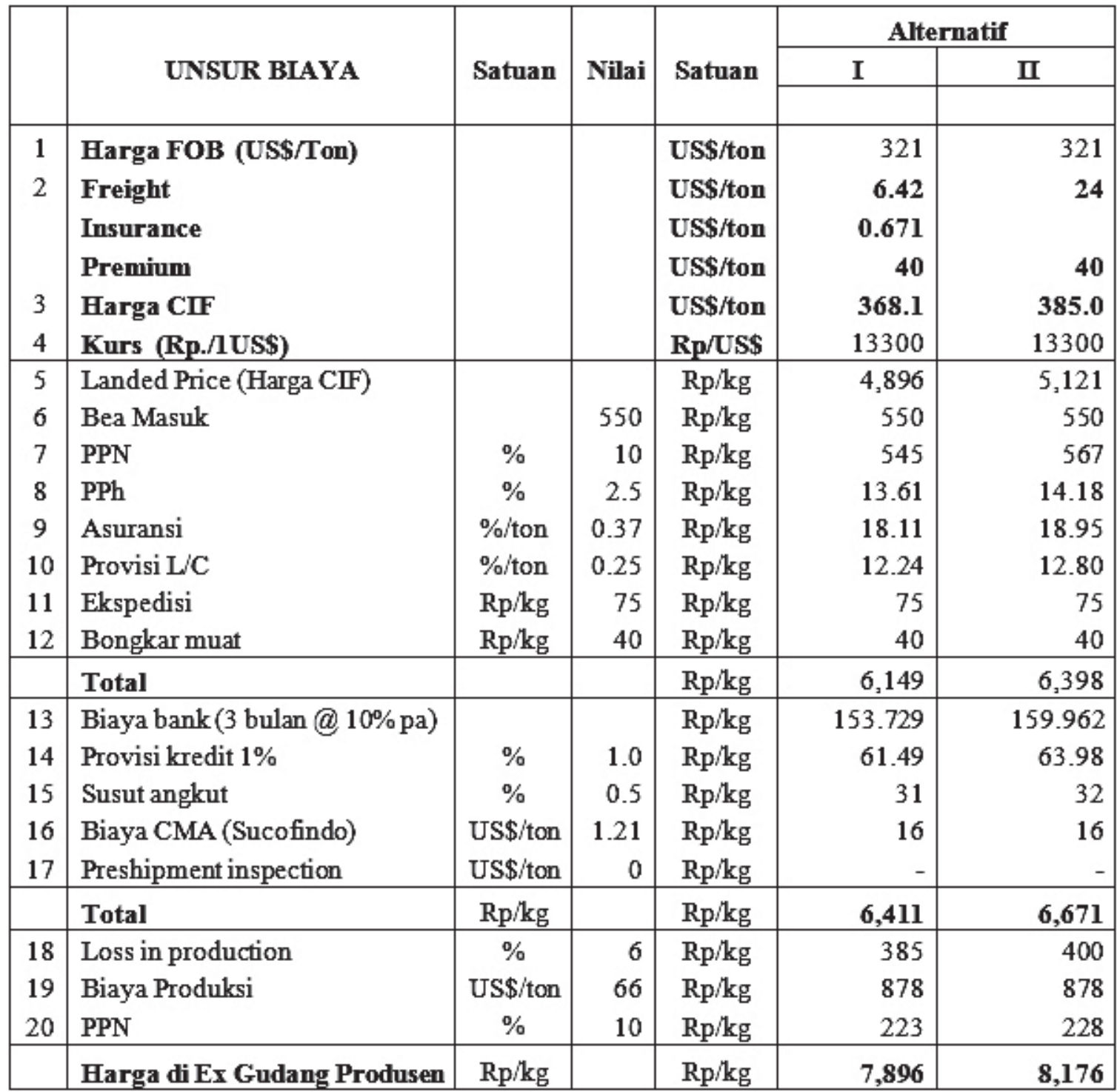

Sumber: data primer (diolah)

Berdasarkan Tabel 2, besaran HBB lelang GKR pada alternatif I sebesar Rp 7.896/Kg dan pada alternatif II sebesar Rp 8.176/Kg. Informasi tersebut dapat dijadikan acuan bahwa besaran HBB GKR antara Rp 7.896/Kg dan Rp 8.176/Kg di gudang penjual (loco) dan belum termasuk biaya lelang yang ditentukan kemudian.

\section{Harga Batas Atas}

Harga Batas Atas (HBA) dengan pendekatan paritas impor juga menggunakan 2 (dua) alternatif berdasarkan besaran komponen biaya yang diperoleh dari FGD. Pada alternatif I, harga tertinggi raw sugar sebesar US\$ 509/Ton, besaran freight dan insurance dihitung berdasarkan Peraturan Menteri Perdagangan Nomor 07/M-DAG/PER/2/2016 Tentang Penetapan Nilai Freight dan Nilai Asuransi Dalam Pengisian Pemberitahuan Ekspor Barang Terkait Penggunaan Term of Delivery 
Cost, Insurance and Freight Untuk Pelaksanaan Ekspor Tahun 2016. Sementara itu biaya produksi tertinggi yang mengacu pada studi Pelitasari (2006) yaitu sebesar US\$ 97/Ton. Sedangkan pada alternatif II, biaya freight and insurance sebesar US\$24/Ton (Tabel 3).

Tabel 3.

Perhitungan Harga Batas Atas

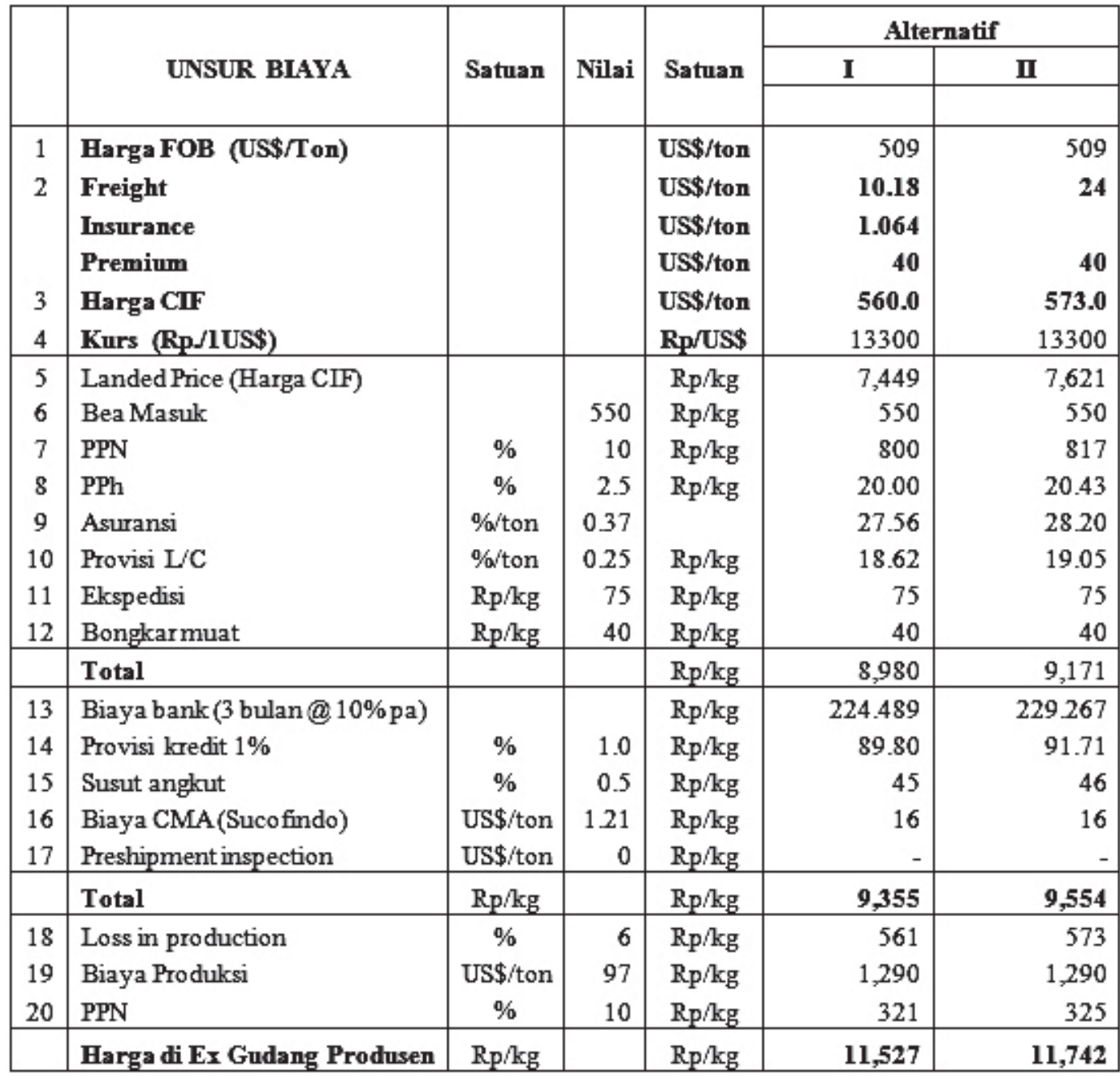

Sumber: data primer (diolah)

Berdasarkan Tabel 3, besaran HBA lelang GKR pada alternatif I sebesar Rp 11.527/Kg dan pada alternatif II sebesar Rp 11.742/Kg. Informasi tersebut dapat dijadikan acuan bahwa besaran HBA GKR antara Rp 11.527/Kg dan Rp 11.742/Kg di gudang penjual (loco) dan belum termasuk biaya lelang yang ditentukan kemudian.

Berdasarkan perhitungan HBB dan HBA lelang GKR, maka terdapat 2 (dua) alternatif, pertama, HBB sebesar Rp 7.869/Kg dan HBA sebesar Rp 11.527/Kg, dan kedua, HBB sebesar Rp 8.176/Kg dan HBA sebesar Rp 11.742/Kg. Jika mengacu harga kontrak industri makanan dan minuman skala besar dengan produsen GKR selama periode Januari 2016 - Juli 2017 pada beberapa perusahaan serta faktur pajak penjualan produsen GKR kepada beberapa industri makanan dan minuman dengan skala menengah, maka rentang harga pada kedua alternatif tersebut masih berada 
pada keseimbangan harga GKR. Kecenderungan pembentukan harga lelang antara produsen GKR dengan industri makanan dan minuman yang berskala menengah berada pada HBA sedangkan pembentukan harga dengan industri makanan dan minuman skala besar berada pada HBB (Gambar $5)$.

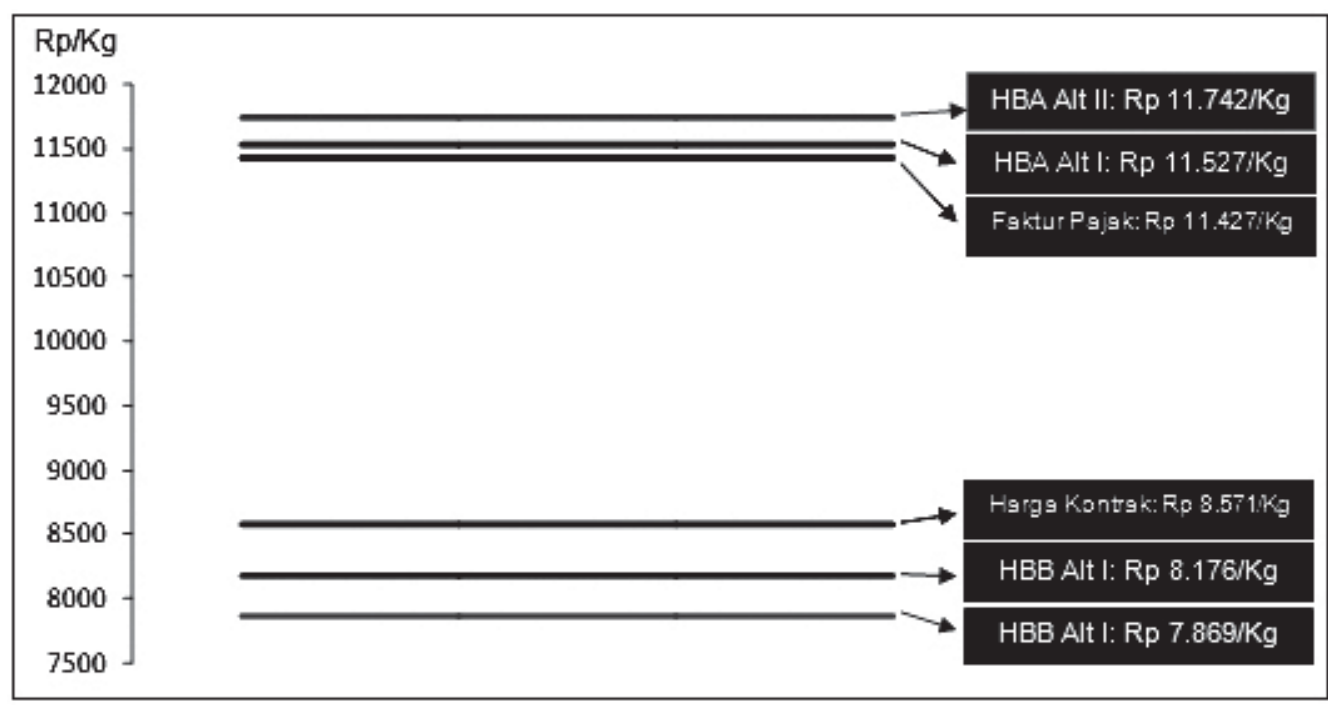

Sumber: Data Primer (diolah)

Gambar 5.

Harga Batas Bawah, Harga Batas Atas, dan Harga GKR Berdasarkan Faktur Pajak Produsen dan Kontrak Industri Makanan dan Minuman

\section{E. PENUTUP}

Pendekatan harga paritas impor GKM digunakan dalam menghitung rentang harga lelang GKR pada PLK. Untuk Harga Batas Bawah (HBB), digunakan harga paritas impor raw sugar dengan menjumlahkan rata-rata FOB terendah ditambah dengan marjin produksi dan distribusi. Sementara untuk Harga Batas Atas (HBA), digunakan rata-rata FOB tertinggi ditambah dengan marjin produksi dan distribusi. Dari perhitungan tersebut, diperoleh HBB berada pada kisaran Rp 7.869/Kg dan Rp 8.176/Kg dan HBA sebesar Rp 11.527/Kg dan Rp 11.742/Kg. Perhitungan tersebut dapat dipertimbangkan karena berada pada "harga keseimbangan” berdasarkan rata-rata harga kontrak yang berkisar antara Rp 8.571/Kg dan Rp 11.427/Kg.

Untuk mendukung kebijakan rentang harga dimaksud, terdapat beberapa hal yang perlu menjadi pertimbangan. Pertama, mengacu kepada Peraturan Menteri Perdagangan Nomor 16/M-DAG/ PER/3/2017, jika kebijakan rentang harga diberlakukan per Juli 2017, maka penerapan HBB dan HBA dikecualikan bagi perusahaan yang sudah memiliki kontrak (existing contract) sesuai dengan masa kontraknya. Hal ini dikarenakan bagi calon peserta lelang dengan existing contract sudah memiliki besaran harga yang berlaku selama periode tertentu. Kedua, penentuan rentang harga bersifat dinamis mengikuti perkembangan harga raw sugar di pasar internasional. Dengan demikian, diperlukan dukungan tim teknis yang terdiri dari perwakilan peserta lelang, pemerintah, dan praktisi bursa komoditas dalam menentukan mekanisme dan forum yang baku untuk mengantisipasi dinamika harga raw sugar. Ketiga, diperlukan fleksibilitas dalam menjamin supply GKR di PLK untuk mendukung penciptaan harga yang efisien dan berada dalam rentang harga yang telah ditetapkan, 
seperti kepastian quota impor selama 1 (satu) tahun. Dengan demikian, penciptaan harga dapat berbasis pada kekuatan permintaan dan penawaran.

\section{F. UCAPAN TERIMA KASIH}

Penelitian ini dilaksanakan atas dukungan dari Pusat Pengkajian Perdagangan Dalam Negeri, Kementerian Perdagangan. Oleh karena itu, disampaikan ucapan terima kasih serta apresiasi kepada pimpinan Pusat Pengkajian Perdagangan Dalam Negeri.

"Penelitian ini dilaksanakan berdasarkan pengamatan kondisi tahun 2017. Data dan informasi yang digunakan semata-mata hanya untuk keperluan penelitian.”

\section{DAFTAR PUSTAKA}

Akanni, K. A. (2013). Agricultural Price Policy, Consumer Demand and Implications for Household Food Security in Nigeria. International Journal of Food and Agricultural Economics, Vol 2 (1), 121-132.

Erba, E. M. \& Novacovic, A. M. (1995). The Evolution of Milk Pricing and Government Intervention in Dairy Markets. EB Series 186308, Cornell University, Department of Applied Economics and Management. Diunduh tanggal 19 Juli 2017 dari https:// ideas.repec.org/p/ags/cudaeb/186308.html

Fajrin, A. E., Hartono, S., \& Waluyati, L. R. (2015). Permintaan Gula Rafinasi Pada Industri Makanan Minuman dan Farmasi di Indonesia. Agro Ekonomi, Vol 26 (2), pp. 150-158.

Galtier, F. (2013). Managing food price instability: Critical assessment of the Dominant Doctrine. Global Food Security 2, pp. 72-81.

Gode, D. K. \& Sunder, S. (2003). Double Auction Dynamics: Structural Effects Of Non-Binding Price Controls. Yale ICF Working Paper No. 00-17. Diunduh tanggal 18 Juli 2017 dari http://ssrn.com/abstract_id=219068

Hartanto, H. S. (2014). Peningkatan Mutu Produk Gula Kristal Putih Melalui Teknologi Defekasi Remelt Karbonatasi. Jurnal Standardisasi, Vol 16 (3), pp. 215-222.

Haryana, A., \& Wicaksena, B. (2016, Juli - September). Gula Rafinasi vs Gula Rakyat di Pasar Konsumen. Media Pusdiklat, Vol 5 (3), 33-38.

Kornher, L. \& Kalkuhl, M. (2013). Food Price Volatolity in Developing Countries and Its Determinants. Quarterly Journal of International Agriculture, Vol 52 (4), 277-308. Diunduh tanggal 07 Juli 2017 dari http://ageconsearch.tind.io/record/173649/files/1_Kornher.pdf

Marpaung, Y. T. F, Hutagaol, P., Limbong, W. H., \& Kusnadi, N. (2011) Perkembangan Industri Gula Indonesia dan Urgensi Swasembada Gula Nasional. Indonesian Journal of Agricultural Economics, Vol 2 (1), 1-14.

Muslim, A. (2014). Peramalan Harga Paritas Kedelai Model Anfis. Widyariset, Vol 17 (1), 13-23.

Pelitasari, L. (2006). Industri Gula Rafinasi di Indonesia: Analisis Struktur Pasar dan Kebijakan. Jurnal Pangan, Vol 46 (25), 63-76. 
Peraturan Menteri Perdagangan Nomor 74/M-DAG/PER/9/2015 Tentang Perdagangan Antarpulau Gula Krista Rafinasi

Peraturan Menteri Perdagangan Nomor 07/M-DAG/PER/2/2016 Tentang Penetapan Nilai Freight dan Nilai Asuransi Dalam Pengisian Pemberitahuan Ekspor Barang Terkait Penggunaan Term of Delivery Cost, Insurance and Freight Untuk Pelaksanaan Ekspor Tahun 2016.

Peraturan Menteri Perdagangan Nomor 16/M-DAG/PER/3/2017 Tentang Perdagangan Gula Kristal Rafinasi Melalui Pasar Lelang Komoditas.

Pusat Kebijakan Perdagangan Dalam Negeri. (2015). Kajian Kebijakan Harga Pangan. Laporan Akhir. Badan Pengkajian dan Pengembangan Kebijakan Perdagangan.

Salam, A. (2009). Distortions in Incentives to Production of Major Crops in Pakistan: 1991-2008. Journal of International Agricultural Trade and Development, Vol 5 (2), 185-208.

Smith, V. L, \& Williams, A. W. (1981). On Nonbinding Price Controls in a Competitive Market. The American Economic Review, Vol 71 (3), 467-474.

Surat Keputusan Menteri Perdagangan Nomor 684/M-DAG/KEP/5/2017 tentang Penetapan Penyelenggara Pasar Lelang Gula Kristal Rafinasi

Susila, W.R. 2005. Pengembangan Industri Gula Indonesia: Analisis Kebijakan dan Keterpaduan sistem Produksi. Desertasi S3. Institut Pertanian Bogor

Tayibnapis, A. Z, Wuryaningsih, L. E., \& Sundari, M. S. (2016). Efforts to Achieve Beyond Sugar in Indonesia. International Journal of Management and Business Studies, Vol 6 (4), pp. 14-22. Diunduh tanggal 07 Juli dari http://www.ijmbs.com/Vol6/4/2-ahmad-zafrullahtayibnapis.pdf

USAID. (2008). Import-Export Parity Price Analysis. FEWS NET Market Guidance, No 1. Washington DC 
